2006-02-01

\title{
Supplementary prescribing by pharmacists in England
}

\author{
Hobson, RJ
}

http://hdl.handle.net/10026.1/3721

10.2146/ajhp050178

American Journal of Health-System Pharmacy

Oxford University Press (OUP)

All content in PEARL is protected by copyright law. Author manuscripts are made available in accordance with publisher policies. Please cite only the published version using the details provided on the item record or document. In the absence of an open licence (e.g. Creative Commons), permissions for further reuse of content should be sought from the publisher or author. 


\title{
Supplementary prescribing by pharmacists in England
}

\author{
PACHET T. HOBSON AND GRAHAM T. SFWFII.
}

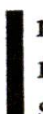
n November 2002, it was announced that supplementary prescribing by nurses and pharmacists was going to become legalized in the United Kingdom, pending legislative changes. ${ }^{1}$ Pharmacists started training in supplementary prescribing in England and Wales in spring $2003,{ }^{2}$ and the first pharmacistwritten prescription was reported in March 2004. ${ }^{3}$ Supplementary prescribing is defined as "a voluntary prescribing partnership between an independent prescriber and a supplementary prescriber, to implement an agreed patient-specific clinical management plan with the patient's agreement,"4 whereby the independent prescriber is a fully registered medical practitioner or dentist whose responsibility is to assess patients with undiagnosed conditions and to determine the clinical management required for those patients, including the prescribing of medications.

Supplementary prescribing was recently extended to registered chiropodists and podiatrists, physiotherapists, radiographers, ${ }^{5}$ and optometrists. ${ }^{6}$ As of June 2005, 532
Purpose. The implementation of supplementary prescribing by pharmacists within primary care trusts (PCTs) and secondary care trusts (SCTs) in England was studied. Methods. A survey was developed and sent to pharmacists in PCTs and SCTs in England who would oversee the implementation of supplementary prescribing by pharmacists. Results. The response rate was $68 \%$ for both surveys. The majority of SCTs and $\mathrm{PCT}$ s intended to implement supplementary prescribing by pharmacists by the end of 2005 ( $57 \%$ and $56 \%$, respectively). The majority of $\mathrm{SCT}$ respondents did not believe that it would be more difficult to recruit designated medical practitioners to supervise supplementary prescribing training for pharmacists as opposed to nurses $(67 \%, n=$ 43), whereas the largest group of PCT pharmacists believed it would be $(47 \%, n=86)$. Within secondary care, the clinical areas in which pharmacists were intending to work as supplementary prescribers were those

(1.2\%) of the 44,951 registered pharmacists in the United Kingdom were registered supplementary prescribing pharmacists. However, not all of these pharmacists are currently utilizing their new prescribing skills. ${ }^{7}$ where they already had established roles. Within primary care, the main clinical areas for pharmacists were influenced by those areas in the new General Medical Services contract Quality and Outcomes Framework for general practitioners.

Conclusion. A survey investigating the implementation of supplementary prescribing by pharmacists in England found that there were significantly more barriers to its establishment within primary care than secondary care settings. Within primary care, supplementary prescribing is being implemented to develop new services. Within secondary care, the supplementary prescribing model is more often used to legitimize services already being provided.

Index terms: Clinical pharmacy; Data collection; Education; England; Pharmaceutical services; Pharmacists; Prescribing; Quality assurance

Am J Health-Syst Pharm. 2006; 63:244-53

The implementation of supplementary prescribing in England is described in this report.

\section{Background}

This new prescribing role has been
RACHEL J. HOBSON, M.SC., M.R.PhARM.S., is Teacher and Practitioner Pharmacist, Department of Pharmacy and Pharmacology, University of Bath and Swindon \& Marlborough NHS Trust, England, United Kingdom. GraHAM J. SEWELL, PH.D., M.R.PHARM.S., M.I.BIOL., C.BIOL, M.R.S.C., C.CHEM., is Professor of Clinical Pharmacy, Department of Pharmacy, Kingston University, Kingston upon Thames, Surrey, and Plymouth Hospitals NHS Trust, England, United Kingdom.

Address correspondence to Ms. Hobson at the Department of
Pharmacy and Pharmacology, University of Bath, Claverton Down, Bath BA2 7AY, England, United Kingdom (r.j.hobson@bath.ac.uk). The authors acknowledge all the pharmacists who completed the survey, Alaster Rutherford for his advice on primary care health policy, and Jenny Scott, Ph.D., for her advice on the presentation and content of this article.

Copyright $\odot$ 2006, American Society of Health-System Pharmacists, Inc. All rights reserved. 1079-2082/06/0201-0244\$06.00.

DOI 10.2146/ajhp050178 
viewed as a major step forward in the development of the pharmacist's role. Although this is the first time that pharmacists are legally able to prescribe in the United Kingdom, pharmacists had already been prescribing medications and had circumvented problems that arose from the legislative controls on prescribing by asking physicians to sign prescriptions that they had written. ${ }^{8,9}$ Several reports from the United Kingdom have identified various prescribing roles, including writing hospital discharge prescriptions and outpatient clinic prescribing. ${ }^{10-17}$ The model of supplementary prescribing may not be suitable for all of these prescribing roles, especially writing discharge prescriptions.

Other models of pharmacist prescribing. The development of pharmacist's prescribing role parallels practice issues in other countries, especially the establishment of collaborative practice agreements in the United States. In this model, the pharmacist has a collaborative arrangement with a physician to prescribe certain medications. ${ }^{18-20}$ In some cases, clinical pharmacy specialists also independently prescribe medications, such as in Veterans Affairs medical centers which allow pharmacists greater freedom to prescribe. ${ }^{21,22}$

The main differences between pharmacist prescribing in the United States and the United Kingdom are that supplementary prescribing represents a more coordinated, centralized approach, as the same model is used nationally. It requires pharmacists to complete a formal training process and demonstrate stipulated competencies (e.g., communication, consultation, and diagnostic skills). While pharmacist prescribers in the United States must be credentialed by their individual institution to provide drug therapy management servic$\mathrm{es}^{23}$ once pharmacists in the United Kingdom have attained the supplementary prescriber qualification, the qualification will be recognized by any secondary care trust (SCT) or primary care trust (PCT).

Collaborative practice protocols are very similar to the clinical management plan used in supplementary prescribing, but a clinical management plan must be written for each patient and must be agreed upon by the patient and the independent prescriber. Rather than using a general protocol that applies to all patients with a certain condition, the clinical management plan is tailored for each patient seen by the prescribing pharmacist.

Since some U.S. pharmacists have been prescribing medications for patients as part of drug therapy management services for a long time, much has been learned from their experiences in the development of pharmacist prescribing in the United Kingdom. Also gleaned from the United States' experience was that even with legislation in place for pharmacist prescribing, certain barriers, such as establishing a working relationship with physician colleagues, must be overcome for a successful service to be developed. ${ }^{23}$ With the aid of such experience, it is hoped that the introduction of supplementary prescribing in the United Kingdom will be more streamlined.

Training and responsibilities of supplementary prescribers. The supplementary prescribing training program comprises at least 26 days of didactic instruction (25 for pharmacists) at a college or university and 12 days of hands-on practice. This training would normally occur over three to six months. ${ }^{4}$ The hands-on practice is supervised by a medical practitioner, known as the designated medical practitioner.

A nurse wishing to train as a supplementary prescriber must be a first-level registered nurse or registered midwife, be able to study at the undergraduate level, have at least three years of postregistration clinical nursing experience, usually be $\mathrm{E}$ grade or above, and have the support of his or her employer. ${ }^{4}$ (See the appendix for a glossary.)

A pharmacist wishing to train as a supplementary prescriber must be fully registered, have the ability to study at the undergraduate level, have at least two years of experience as a pharmacist postregistration, and have the support of his or her employer. ${ }^{4}$

A chiropodist-podiatrist, physiotherapist, or radiographer wishing to become a supplementary prescriber must be able to study at the undergraduate level, have at least three years of relevant postqualification experience, and have the support of his or her employer. ${ }^{5}$ (It is anticipated that optometrists will have similar training requirements.)

The supplementary prescriber is responsible for the continuing care of patients who have been clinically assessed by an independent prescriber. This continuing care may include prescribing, which will usually follow clinical guidelines and be consistent with individual treatment plans, or will continue established treatments by writing repeat prescriptions, with the authority to adjust the dosage or dosage form in accordance with the patient's needs and as defined by a clinical management plan. There should be a provision for regular clinical review by the assessing clinician. ${ }^{24}$

Supplementary prescribing is primarily intended for managing specific chronic medical conditions to provide patients with quicker and more efficient access to medicines. By making the best use of the skills of trained nurses and pharmacists, physicians will have more time to focus on patients with more complicated conditions and more complex treatments. ${ }^{4}$

Although legislation permits the introduction of supplementary prescribing throughout the United Kingdom, Scotland, Wales, and Northern Ireland must still decide whether and how it is implemented for the National Health Service (NHS) in their countries. ${ }^{4}$ 
Further information about supplementary prescribing can be found at the Department of Health's Web site (www.dh.gov.uk/Home/fs/en).

Topics requiring investigation. There is no national strategy to guide which clinical areas supplementary prescribers should practice in or which areas of expertise should be developed. Without this, supplementary prescribing will develop in an ad hoc fashion. ${ }^{25}$

Although supplementary prescribing has been a very topical subject in the pharmacy profession, there is no information available on how supplementary prescribing is currently being implemented within primary and secondary care. Also, practitioners hoping to establish independent prescribing rights (where the pharmacist, nurse, or other health care professional has full responsibility for the diagnosis, monitoring, and ongoing treatment of a specified patient's condition) will benefit from the experience gained with supplementary prescribing. The legislation for independent prescribing by pharmacists is estimated to be in place by the end of $2005,{ }^{26}$ after the consultation period finished in May 2005. ${ }^{27}$

The objectives of this study were to establish (1) how chief pharmacists in SCTs and PCT pharmacists were implementing pharmacist supplementary prescribing within their trusts, (2) the number of pharmacists being trained as supplementary prescribers, (3) the types of pharmacists being trained, and (4) the area in which the pharmacist supplementary prescriber would be working.

\section{Methods}

A questionnaire was designed and sent to pharmacists in PCTs and SCTs in England who would oversee the implementation of supplementary prescribing by pharmacists. Questionnaires sent to SCTs were addressed to the chief pharmacist.

General practices in England are grouped into PCTs, which hold the health care budget (for both primary and secondary care) for approximately 120,000 patients. $^{28}$ Pharmacists are employed by PCTs to control drug budgets. Some PCT pharmacists are involved in policy development. Most PCT pharmacists work with individual general practitioners to assist with drug audits and medication review. Because some PCTs do not employ pharmacists or employ them on a sessional basis, the questionnaires sent to PCTs were addressed to the PCT pharmacist in the absence of a named pharmaceutical adviser (i.e., PCT pharmacist involved in policy development in the PCT). PCTs that did not employ a pharmacist were excluded from the survey.

Questionnaire development. Construction of the questionnaire was aided by literature review. Policy-making and academic pharmacists in England were identified and asked key questions with respect to supplementary prescribing. To develop a more detailed perspective on the issues and risks surrounding supplementary prescribing, individual unstructured interviews were conducted with a clinical governance leader, a nurse educator on supplementary prescribing, a chief executive of a hospital, and a clinical governance coordinator.

These data were used to suggest topics for discussion in a focus group. The focus group was arranged to more clearly define the key areas that the questionnaire should cover. The focus group's participants included a professor of pharmacy practice, a nurse senior lecturer who had developed a supplementary prescribing training course, a chief pharmacist, and a clinical governance leader. The focus group also discussed issues surrounding (1) the risks and benefits of supplementary prescribing and its implementation and (2) designated medical practitioners, such as availability and quality. Responsibility and accountability were also addressed. The focus group's discussions were audiotaped and transcribed verbatim.

One questionnaire was designed for chief pharmacists of secondary care acute hospital trusts, and a very similar questionnaire was designed for PCT pharmacists. The questionnaire was divided into three sections: demographic questions (section A), questions about the recruitment of designated medical practitioners and the implementation of supplementary prescribing within the trust (section B), and questions regarding respondents' attitude about supplementary prescribing (section C). Results from section $C$ are not discussed in detail here. Questionnaires were numbered to maintain respondent anonymity.

The multicenter research and ethics committee approved this study.

Validation and pilot testing. To assess the validity of the SCT questionnaire, one chief pharmacist was observed while completing the questionnaire and discussed any ambiguities that arose with the researcher, and another chief pharmacist completed the questionnaire and mailed it back with written comments. Minor adjustments were then made to clarify these ambiguities.

To validate the PCT questionnaire, two PCT pharmacists completed the questionnaire; one provided feedback via telephone and the other provided written feedback. Reliability of the survey tool was not tested, as the questionnaire would have produced survey fatigue if retested in the same limited population.

In February and March 2004, the SCT questionnaire was pilot tested in 17 randomly selected SCT hospitals from the sample of 168 . At the same time, the PCT questionnaire was sent to 30 randomly selected PCT pharmacists from the sample of 303 . After the pilot questionnaires were completed, some questions were removed to reduce the length of the questionnaire and some questions 
had options added to or removed from them.

Questionnaire distribution. Both questionnaires were distributed in May 2004. The SCT questionnaire was mailed to chief pharmacists within every NHS trust in England providing acute hospital services. Single hospitals within each trust were identified using a combination of the Chemist and Druggist Directo$r y^{29}$ and the Guild of Healthcare Pharmacists' chief pharmacist mailing list. ${ }^{30} \mathrm{~A}$ random-number generator was used to randomly send a questionnaire to one hospital in each trust. Completed surveys by SCT pharmacists whose hospital had merged with another trust were not used in the analysis.

The PCT questionnaire was sent to the PCT pharmacist or pharmaceutical advisor within each PCT. PCTs, pharmaceutical advisers, and PCT pharmacists were identified using Medendium. ${ }^{31}$

Questionnaires were sent to 151 SCT hospitals. Eight of these hospitals had merged with another trust or were not an acute trust and were excluded from the analysis. A total of 273 PCTs were included in the study. Two of these trusts were excluded from the analysis either because they were not a PCT or they did not employ a pharmacist.

Questionnaires were accompanied by a letter explaining the purpose of the study and a postage-paid envelope for the return of the questionnaire. Follow-up was conducted via a second mailing of the questionnaire to nonresponders after 3 weeks, and a follow-up telephone call after a further 4 weeks (SCTs) or another questionnaire mailing (PCTs) (the larger sample of PCTs required the use of postal follow-up). After 3 more weeks, one last mailing of the questionnaire was sent to any remaining nonresponders. The deadline for accepting questionnaires was set at 13 weeks after the date of the original mailing.
Data analyses. Data obtained from returned questionnaires were coded and analyzed using SPSS, version 11 (SPSS Inc., Chicago, IL). The association between variables was assessed using nonparametric chisquare tests, the Kruskal-Wallis test, the Mann-Whitney $U$ test, and bivariate correlations (Spearman's rho), where appropriate.

\section{Results}

Demographics. Of the 143 hospitals that received a questionnaire, responses were received from $97(68 \%)$. No particular patterns emerged when response rate was assessed by region.

Sixty-two percent of hospital responses $(n=58)$ came from chief pharmacists of district general hospitals, 35\% $(n=33)$ from teaching hospitals, and $3 \%(n=3)$ from tertiary specialist hospitals. Hospital sizes varied, ranging from 201-400 to more than 1500 beds, with the most common being 401-600 beds $(n=$ 23) and 1001-1500 beds $(n=23)$. SCT respondents had most commonly been pharmacists for more than 25 years $(44 / 94[47 \%])$ and chief pharmacists for more than 16 years $(26 / 92[28 \%])$ (the questionnaire offered ranges of years as possible responses). The mean \pm S.D. number of full-time-equivalent pharmacists employed by SCTs was $26 \pm 19$ (range, 6-126).

Of the 271 PCTs, $183(68 \%)$ responded. PCT respondents had most commonly been pharmacists for 1115 years $(45 / 181[25 \%])$ and PCT pharmacists for 3-4 years $(62 / 180$ [34\%]). Primary care responses indicated that the mean \pm S.D. number of full-time-equivalent pharmacists employed by PCTs was $3 \pm 2$ (range, 0.25-12).

Pharmacist supplementary prescribing. SCTs. When asked about their intentions to implement supplementary prescribing by pharmacists, the majority of chief pharmacists $(57 \%, n=55)$ stated that they intended to implement the service by the end of 2005 , and $14 \%(n=14)$ stated that they would not have supplementary prescribing by pharmacists implemented by the end of 2005 .

The total number of pharmacists employed by the SCT was significantly associated with the intention to implement pharmacist supplementary prescribing $(p=0.004$, Kruskal-Wallis test, $d f=3$ ). As the number of pharmacists employed by the trust increased, the more common the intention to implement supplementary prescribing. The chief pharmacists who intended to implement pharmacist supplementary prescribing planned to train 0-14 pharmacists (mean, 3) during 2004 and 1-24 pharmacists (mean, 3 ) during 2005.

There was a significant relationship between the number of pharmacists to be trained as supplementary prescribers during 2004 and the number of beds in the hospital, with the highest mean rank for hospitals with 601-800 beds ( $p=0.012$, Kruskal-Wallis test, $d f=5$ ). This was also found to be the case for 2005 ( $p$ $=0.003$, Kruskal-Wallis test, $d f=5)$.

A moderate positive correlation existed between the total number of pharmacists employed by the trust and the number of pharmacists to be trained as supplementary prescribers during $2004(r=0.54, p<0.001)$ and $2005(r=0.57, p<0.001)$.

Teaching hospitals were significantly more likely than other types of hospitals to train more pharmacists in $2005(p=0.026$, Kruskal-Wallis test, $d f=2)$.

The majority of chief pharmacists $(85 \%)$ stated that they intended to train $D$ grade pharmacists as supplementary prescribers; $70 \%$ intended to use E grade pharmacists. The different clinical areas of supplementary prescribing targeted by chief pharmacists appear in Table 1.

Teaching hospitals were also more likely than other hospital types to offer more pharmacist supplementary prescribing activities $(p=0.007$, 
Kruskal-Wallis test, $d f=2$ ). A moderate positive correlation was found between the total number of pharmacists employed by the trust and the total number of pharmacist supplementary prescribing activities offered $(r=0.59, p<0.001)$. A moderate positive correlation was also found between the total number of pharmacist supplementary prescribing activities (i.e., the different clinical areas) and the total number of pharmacist nonsupplementary prescribing activities $(r=0.53$, $p=0.001$ ).

The person most commonly listed to assume prescribing responsibility in the supplementary prescriber's absence was a junior doctor (56\%), followed by a consultant physician (39\%) or another pharmacist supplementary prescriber $(37 \%)$. Some pharmacists indicated that no one would provide the service $(24 \%)$ or that they did not know who would provide the service (13\%).

Additional training requirements for pharmacist supplementary prescribers most commonly included experience in the clinical area in which the pharmacist supplementary prescriber would be working (89\%), followed by a clinical diploma (73\%) and the completion of continuing professional development requirements from the Royal Pharmaceutical Society of Great Britain (55\%).

PCTs. The majority of PCT pharmacists $(56 \%)$ intended to implement supplementary prescribing by the end of 2005; 9\% did not. Some PCT pharmacists did not know their intentions (35\%).

The total number of pharmacists employed by the trust was significantly associated with the intention to implement supplementary prescribing by pharmacists $(p=0.008$, Kruskal-Wallis test, $d f=3$ ). The pharmacists who intended to implement pharmacist supplementary prescribing planned to train 0-6 pharmacists (mean, 2) in 2004 and 1-10 pharmacists (mean, 3) in 2005.

Table 1.

Clinical Areas To Be Undertaken by Pharmacists with Supplementary Prescribing Authority ${ }^{a}$

\begin{tabular}{|c|c|c|}
\hline \multirow[b]{2}{*}{ Area } & \multicolumn{2}{|c|}{ No. (\%) Respondents } \\
\hline & $\begin{array}{c}\text { Secondary } \\
\text { Care }(n=53)\end{array}$ & $\begin{array}{c}\begin{array}{c}\text { Primary Care } \\
(n=75)\end{array} \\
\end{array}$ \\
\hline Hypertension & $\ldots^{\mathrm{b}}$ & $40(53)$ \\
\hline CHD or hyperlipidemia & & $35(47)$ \\
\hline Diabetes mellitus & $5(9)$ & $27(36)$ \\
\hline TPN or nutrition & $19(36)$ & $\ldots$ \\
\hline Asthma & & $25(33)$ \\
\hline Oncology-hematology & $16(30)$ & $\ldots$ \\
\hline Heart failure or cardiology & $13(25)$ & $\ldots$ \\
\hline COPD & & $18(24)$ \\
\hline HIV & $12(23)$ & $\ldots$ \\
\hline Renal & $12(23)$ & $\ldots$ \\
\hline Anticoagulation & $10(19)$ & $7(9)$ \\
\hline Surgery or orthopedics & $9(17)$ & $\ldots$ \\
\hline Gastrointestinal or PPIs & & $12(16)$ \\
\hline Pain control & $8(15)$ & $7(9)$ \\
\hline Rheumatology & $7(13)$ & $5(7)$ \\
\hline Medication review & & $7(9)$ \\
\hline Hospital admissions & $5(9)$ & \\
\hline Care of the elderly & $5(9)$ & $6(8)$ \\
\hline Cystic fibrosis & $5(9)$ & $\ldots$ \\
\hline Hospital discharge planning & $5(9)$ & \\
\hline Mental health & $5(9)$ & $4(5)$ \\
\hline Pediatrics & $4(8)$ & $\ldots$ \\
\hline Other & $30(57)$ & $17(23)$ \\
\hline
\end{tabular}

${ }^{\mathrm{a}} \mathrm{CHD}=$ coronary heart disease, TPN = total parenteral nutrition, $\mathrm{COPD}=$ chronic obstructive pulmonary disease, HIV = human immunodeficiency virus, PPIs = proton pump inhibitors.

${ }^{b}$ Area not offered on questionnaire or provided by respondents.

When asked who they intended to train as supplementary prescribers, the most common response was primary care-based pharmacists (in PCTs) (67\%), followed by general practitioner practice-based pharmacists (55\%) and community pharmacists $(45 \%)$. The different clinical areas in which PCT pharmacists planned to implement supplementary prescribing are listed in Table 1 .

The person most commonly listed to assume responsibility for prescribing in the supplementary prescriber's absence was a general practitioner (37\%), followed by a nurse supplementary prescriber $(21 \%)$ or a pharmacist supplementary prescriber (15\%). A large percentage of pharmacists indicated that no one would provide the service in the prescriber's absence (32\%); $26 \%$ did not know who would provide the service.

Additional training requirements for the pharmacist supplementary prescriber most commonly included the completion of continuing professional development requirements offered by the Royal Pharmaceutical Society of Great Britain (64\%), followed by clinical experience in the area in which the pharmacist supplementary prescriber would be working (60\%) and a clinical diploma (50\%).

Implementation of supplementary prescribing. The factors affecting the recruitment of designated medical practitioners are presented in Table 2.

SCTs. When asked if it would be easier to recruit designated medical practitioners for nurses rather than pharmacists, $44 \%$ of chief pharmacists did not believe it would be, $22 \%$ believed it would, and $30 \%$ did not know (data were missing for $4 \%$ ). Pharmacists who believed it would be easier to recruit designated medical practitioners for nurses rather than pharmacists responded that nurses al- 
ready have an established working relationship with doctors (50\%) and that nurses are already working as prescribers $(31 \%)$. Pharmacists who did not believe it would be easier indicated that (1) the problems are identical for nurses and pharmacists (31\%), (2) the ease of recruitment would be dependent on the relationship with the designated medical practitioner and the benefit received by the designated medical practitioner (27\%), and (3) pharmacists are highly specialized and well regarded (23\%).

PCTs. The individuals charged with implementing pharmacist supplementary prescribing within each PCT are listed in Table 3. When asked if it would be easier to recruit designated medical practitioners for nurses rather than pharmacists, $47 \%$ of pharmacists believed it would be easier, $28 \%$ did not, and 25\% did not know. Those who agreed with the statement indicated that nurses already have an established working relationship with doctors $(87 \%, n=69)$ and that nurses are already working as prescribers $(27 \%, n=21)$. Respondents also stated that (1) general practitioners do not understand pharmacists' skills and have no relationship with them $(15 \%, n=12)$, (2) it would be more difficult for employees of trusts $(11 \%, n=9)$, and (3) pharmacists are viewed as business focused or non-NHS employees $(10 \%, n=8)$.

The most common reasons given among those who disagreed with the statement were (1) the problems are identical for nurses and pharmacists ( $48 \%, n=13$ ), (2) pharmacists have good working relationships with other health care professionals $(26 \%, n$ $=7$ ), (3) it would be dependent on the relationship with and the benefit received by the designated medical practitioner $(15 \%, n=4)$, and (4) it depends on whether the person is a trust employee $(15 \%, n=4)$.

\section{Discussion}

Pharmacist supplementary prescribing. The percentages of chief

Table 2 .

Factors Affecting Recruitment of Designated Medical Practitioners in Secondary and Primary Care

\begin{tabular}{lcc}
\hline \multicolumn{1}{c}{ Factor } & \multicolumn{2}{c}{ No. (\%) Respondents } \\
\cline { 2 - 3 } & $\begin{array}{c}\text { Secondary } \\
\text { Care }(\boldsymbol{n}=\mathbf{9 3 )}\end{array}$ & $\begin{array}{c}\text { Primary Care } \\
(\boldsymbol{n}=\mathbf{1 7 9 )}\end{array}$ \\
\hline Time commitment & $65(70)$ & $146(82)$ \\
Concurrent workload & $57(61)$ & $140(78)$ \\
Benefit to mentor & $53(57)$ & $110(61)$ \\
Relationship with the trainee & $47(51)$ & $75(42)$ \\
Commitment and understanding & $47(51)$ & $93(52)$ \\
Lack of funding & $20(22)$ & $119(66)$ \\
None & $2(2)$ & $4(2)$ \\
Other & 0 & $7(4)$ \\
\hline
\end{tabular}

Table 3.

Person or Group Responsible for Implementing Supplementary Prescribing by Pharmacists within Primary Care Trusts $(n=181)$

\begin{tabular}{lc}
\multicolumn{1}{c}{ Person or Group } & No. (\%) Respondents \\
\hline Pharmaceutical adviser & $118(65)$ \\
Nonmedical prescribing group & $58(32)$ \\
Medicines management committee & $36(20)$ \\
Clinical governance lead & $7(4)$ \\
Community pharmacy development group & $4(2)$ \\
Nurse prescribing facilitator & $3(2)$ \\
Lead pharmacist for prescribing & $2(1)$ \\
Head of work force development & $1(1)$ \\
Not yet decided & $29(16)$ \\
Do not know & $3(2)$ \\
No one & $2(1)$ \\
\hline
\end{tabular}

pharmacists and PCT pharmacists intending to implement supplementary prescribing by the end of 2005 were similar. It was most common within PCTs for PCT and general practitioner practice-based pharmacists rather than community pharmacists to be trained as supplementary prescribers. Community pharmacists often lack online access to patients' medical records, lack a private area within the pharmacy for patient consultation, have difficulty obtaining funding from the PCT, and lack established working relationships with local general practitioners.

Although most SCT respondents indicated that junior doctors would provide the supplementary prescribing in the absence of the pharmacist supplementary prescriber, it has been suggested that having a pharmacist provide this service would result in a superior prescription service in terms of safety and overall quality of the prescriptions. ${ }^{14,32-35}$ Whether it is acceptable for the supplementary pharmacist's annual leave, sick leave, and overnight or weekend shifts to be provided by a more inferior service is an issue that must be addressed. The goal should be the provision of a 24-hour service for hospitalized patients; however, the limited number of pharmacists would make this impossible for most hospital trusts.

The most common clinical areas served by pharmacist supplementary prescribers in secondary care reflect those areas where pharmacist prescribing input has already been established (Table 1). The most common area in which chief pharmacists were training pharmacists to be supplementary prescribers was total parenteral nutrition, an area in which pharmacists are already work- 
ing as supplementary prescribers. ${ }^{36,37}$ Pharmacists have a long-established role in the nutrition teams of most hospitals ${ }^{38}$ and provide key input in the individual composition of total parenteral nutrition prescriptions. Pharmacists also have established roles in oncology, hematology, cardiology, and anticoagulation ${ }^{37,39-49}$ and have prescribing roles in these areas. It is not surprising that pharmacists are being trained as supplementary prescribers in renal care, rheumatology, HIV care, and care of the elderly. ${ }^{36,37,41,50}$ Again these are areas in which pharmacists have established clinical roles ${ }^{51,52}$ and pharmacist prescribing is well suited due to the polypharmacy, complexity of the medication regimen (e.g., drug interactions), and multiple concurrent conditions often associated with these patients.

Some therapeutic areas targeted for supplementary prescribing have associated National Service Frameworks (NSFs) and published national guidance available.

The publication of the NSF for older people, which sets standards in care, recommends that all elderly people have their medications reviewed at least annually (every six months for those taking four or more medicines) and get more help from pharmacists in using their medicines. ${ }^{53}$ Therefore, this area should be targeted for pharmacist supplementary prescribing.

The NSF for renal services, published in January 2004, emphasized the extensive role that pharmacists can have in optimizing medication use. ${ }^{54}$ Again, this area would be appropriate for supplementary prescribing.

Another therapeutic area commonly identified as one in which pharmacists were being trained as supplementary prescribers was surgicalorthopedic preadmission clinics. As described for other therapeutic areas, pharmacists had a welldeveloped role in this area before the advent of supplementary prescrib- ing. Pharmacists were involved in taking medication histories, writing the patient's current medication onto the inpatient drug chart during these clinics, and following protocols for standard antibiotic prophylaxis and thromboprophylaxis, also written on the inpatient drug chart. ${ }^{9-12,55-58}$ By training pharmacists as supplementary prescribers, doctors will no longer need to cosign inpatient drug charts and pharmacists' role as prescribers will be legitimized.

Primary care has focused its supplementary prescribing training on quite different areas than has secondary care. This may be due to the implementation of the new General Medical Services (GMS) contract for general practitioners. ${ }^{59}$ In this new contract, payment for services focuses on improving the overall quality of clinical care for patients. Within the GMS contract, the Quality and Outcomes Framework specifies disease categories where more comprehensive service provision will be rewarded with more substantial payments. The top five clinical areas identified for PCT pharmacist supplementary prescribers (Table 1) were specified in the Quality and Outcomes Framework. General practitioner practices will target the development of services in these areas to enhance their payments. These areas are also subject to detailed guidance published over the past few years in the form of $\mathrm{NSFs}^{60,61}$ and specialist guidelines. ${ }^{62-64}$ These clinical areas are extremely suitable for pharmacist supplementary prescribing, as the clinical management plans can refer the pharmacist to such national guidelines.

Pharmacist supplementary prescribing in mental health appears to be uncommon in both primary and secondary care. This is rather surprising, considering that mental health was identified in the Quality and Outcomes Framework and that there is an NSF for this therapeutic area ${ }^{65}$

The United Kingdom Psychiatric Pharmacy Group and College of
Mental Health Pharmacists (CMHP) believe that, in order to be a competent supplementary prescriber in mental health, a pharmacist must be a member of CMHP in addition to receiving the required supplementary prescribing training. ${ }^{66}$ This is the only specialist clinical pharmacy group to have any additional requirements. These additional requirements may have a negative effect on pharmacists wishing to become supplementary prescribers in this area. Alternatively, they may reflect an attitude within the mental health community that prescribing in this area is more complex than in other therapeutic areas.

PCT respondents indicated that in the absence of the pharmacist supplementary prescriber, a nurse supplementary prescriber would provide the service if a general practitioner was not going to be used. This may be because primary care has a large number of qualified nurse supplementary prescribers and the therapeutic areas that most pharmacists are going to work in have clear, detailed guidance available and are not as complex as some of the therapeutic prescribing areas in secondary care. However, it also suggests that no distinction is being made between the type of prescribing that a pharmacist in, for example, a cardiac clinic will participate in compared with that of a nurse. If the type of prescribing is identical for both professions, a nurse would be chosen to run the clinic because the salaries for experienced clinical pharmacists and community pharmacists are higher than nurses'. This means that pharmacists will have to establish areas (such as more complex polypharmacy areas) to use their more expensive clinical expertise and that a distinction will have to be made about what types of clinics the different professions are going to offer in each clinical area.

Implementation of supplementary prescribing. As there is not a 
standardized competency framework for pharmacists once they have qualified to practice, there is no differentiation between the skills necessary to practice as a clinical pharmacist versus a senior clinical pharmacist, making it difficult for doctors to understand the knowledge and competency of different pharmacists when requesting advice. The development of supplementary prescribing will compound their confusion when trying to distinguish among the skills of various pharmacists. ${ }^{67}$ Recent work has been undertaken to develop a competency framework for pharmacists within primary and secondary care ${ }^{68}$ Although this will standardize the skills of senior clinical pharmacists from trust to trust, it will not differentiate the pharmacists who are supplementary prescribers.

Community pharmacists will also have difficulty understanding which health care professional has which type of prescribing rights when presented with a prescription. The development of supplementary prescribing will also cause confusion for the general public, as some community pharmacies will have pharmacists that can prescribe medicines and others will not.

Although both PCT and SCT respondents rated time commitment and workload as the two most important factors affecting recruitment of designated medical practitioners, PCTs highlighted the lack of funding for the role. This was not an issue for SCTs, as all doctors are employees of the NHS.

In PCTs, general practitioners receive payment individually based on the services they offer. To supervise a supplementary prescribing trainee, a general practitioner may expect to receive payment for it, unless there is a clear business case presented to his or her practice, outlining the benefits that the service will provide. This may make it difficult for nurses and pharmacists who are not employees of a practice to recruit a designated medical practitioner to supervise their training.

The people charged with implementing supplementary prescribing for pharmacists in primary care varied (Table 3). For primary care, this array of different people will inevitably lead to different PCTs having different priority levels for the implementation of supplementary prescribing. Implementation will also be affected by the new community pharmacy contract, which is currently being implemented. ${ }^{69}$ The first and second tiers of the contract are termed "essential and advanced services," which will be funded via a national agreement. However, the third tier of enhanced services, which may include supplementary prescribing services, will be commissioned by PCTs, meaning that if a PCT does not see a need for a particular service, pharmacists will not get paid for providing it. $^{70}$

It has been suggested that further reorganization of PCTs will happen now that the general election has occurred, whereby mergers of PCTs would reduce their number from 303 to $100-150$ across England. This is because there is a growing belief that many trusts are ineffective organizations, unable to commission acute health care effectively and unable to fulfill public health responsibilities. ${ }^{71}$ If this reorganization occurs, then the commissioning of enhanced services for pharmacies may be even more difficult.

The development of supplementary prescribing services will also need to make sense for community pharmacies. Although many community pharmacies offer certain services, such as cholesterol testing, free of charge, smaller, independent pharmacies cannot offer such services without recompense. It is extremely important that pharmacy businesses maintain a united front when negotiating payment for supplementary prescribing services from PCTs.
The lack of a national strategy to guide which therapeutic areas are more in need of pharmacist supplementary prescriber's input may mean that some patient groups may still have reduced access to services, and that doctors working within these areas will still have unmanageable workloads and waiting lists. It would therefore seem sensible for guidance to be made available, suggesting target areas where this role development is more urgent than others.

The way in which supplementary prescribing is being implemented in primary and secondary care suggests that one model of nonmedical prescribing may not be feasible. Primary and secondary care are very different in terms of funding, interprofessional relationships, and methods of working, suggesting that slightly different models of nonmedical prescribing may be needed. Because of the necessity to produce a clinical management plan for the patient's condition that is being treated by the pharmacist supplementary prescriber, supplementary prescribing is more suited for the management of chronic conditions in primary care rather than the acute conditions seen in secondary care.

The rationale for implementing supplementary prescribing must also be examined. It has been suggested that the main driver relates to resource issues within the NHS and the curbing of escalating health care costs rather than improving the quality of prescribing. The impending development of independent prescribing may offer more flexibility for SCT nonmedical prescribers and address some of the highlighted difficulties that community pharmacists will face with respect to supplementary prescribing. In fact, independent prescribing rights may be more welcomed than the current supplementary prescribing model.

Study limitations. The response rate was sufficient when compared with similar questionnaire sur- 
veys. ${ }^{17,72,73}$ Telephone follow-up of chief pharmacists was difficult, as they are extremely busy and their secretaries preferred to take a message rather than let the lead researcher speak with the chief pharmacist. This may have reduced the response rate. The list of PCT pharmacists named in the spring 2003 guide for PCTs was often inaccurate. ${ }^{31}$ On subsequent mailings, the named pharmacist was removed and changed to "primary care trust pharmacist" to improve the response rate.

Although it would have been preferable to use the same follow-up methodology for both surveys, telephone follow-up was not conducted for the PCT pharmacists. Instead, an extra mailing was sent because it would have taken more time than was available to complete the telephone follow-up for such a large sample. As the same response rate was achieved for both questionnaire surveys, the slightly different followup methodology does not appear to have affected the integrity of the survey results.

\section{Conclusion}

A survey investigating the implementation of supplementary prescribing by pharmacists in England found that there were significantly more barriers to its establishment within primary care than secondary care settings. Within primary care, supplementary prescribing is being implemented to develop new services. Within secondary care, the supplementary prescribing model is more often used to legitimize services already being provided.

\section{References}

1. National Health Service. Wider prescribing powers proposed. www.nhs.uk/ england/news/article.aspx?newsID=17183 (accessed 2005 Nov 9).

2. Root G. Supplementary prescribing-a groundbreaking opportunity. Pharm $\mathrm{J}$. 2003; 270:19-20.

3. First prescription signed by a hospital pharmacist. Pharm J. 2004; 272:369. News.

4. Department of Health. Supplementary prescribing by nurses and pharmacists within the NHS in England-a guide for implementation. www.dh.gov.uk/ assetRoot/04/06/84/31/04068431.pdf (accessed 2005 Nov 9).

5. Department of Health. Supplementary prescribing by nurses, pharmacists, chiropodists/podiatrists, physiotherapists and radiographers within the NHS in England. www.dh.gov.uk/assetRoot/04/ 11/00/33/04110033.pdf (accessed 2005 Nov 9).

6. Supplementary prescribing extended to optometrists. Pharm J. 2005; 275:37. News.

7. Pharmacist prescribing: the reality. Pharm I. 2004; 273:483.

8. Hobson RJ, Sewell GJ. Responsibility, accountability and factors influencing provision of pharmacist transcription of discharge prescriptions. Int J Pharm Pract. 2004; 12:163-8.

9. McIntyre F, Manson K. Pre-admission clinics: extending the delivery of pharmaceutical care. Pharm J. 2004; 272:478-9.

10. Lord S. The interface: steps towards seamless care. Hosp Pharm. 1999; 6:83-4.

11. Hebron B, Jay C. Pharmaceutical care for patients undergoing elective ENT surgery. Pharm J. 1998; 260:65-6.

12. Hick HL, Deady PE, Wright DJ et al. The impact of the pharmacist on an elective general surgery pre-admission clinic. Pharm World Sci. 2001; 23:65-9.

13. Booth CD. Pharmacist-managed anticoagulant clinics: a review. Pharm J. 1998; 261:623-5.

14. Milliken B, Rea Y. A clinical pharmacist's contribution to discharge planning and patient counselling. Pharm J. 1997; 258:777-8

15. Boorman S, Cairns C. Another way forward for pharmaceutical care: a teambased clinical pharmacy service. Pharm J. 2000; 264:343-6.

16. Cattell R, Conroy C, Sheikh A. Pharmacist intergration into the discharge process: a qualitative and quantitative impact assessment. Int J Pharm Pract. 2001; 9:59-64.

17. Hobson RJ, Sewell GJ. A national survey of pharmacist transcribing of discharge prescriptions. Int J Pharm Pract. 2003; 11:89-95.

18. Carmichael JM, O'Connell MB, Devine B et al. Collaborative drug therapy management by pharmacists. Pharmacotherapy. 1997; 17:1050-61.

19. Webb CE. Prescribing medications: changing the paradigm for a changing health care system. Am I Health-Syst Pharm. 1995; 52:1693-5.

20. Galt KA. The key to pharmacist prescribing: collaboration. Am J Health-Syst Pharm. 1995; 52:1696-9.

21. Farrell J, North-Lewis P, Cross M. Pharmacist prescribing in the United States. Pharm J. 1997; 259:187-90.

22. Clause S, Fudin J, Mergner A et al. Prescribing privileges among pharmacists in Veterans Affairs medical centers. Am J Health-Syst Pharm. 2001; 58:1143-5.

23. Kuo GM, Buckley TE, Fitzsimmons DS et al. Collaborative drug therapy manage- ment services and reimbursement in a family medicine clinic. Am J Health-Syst Pharm. 2004; 61:343-54.

24. Department of Health. Review of prescribing, supply and administration of medicines: final report. www.dh.gov.uk/ assetRoot/04/07/71/53/04077153.pdf (accessed 2005 Nov 9).

25. Strategy needed for clinical areas in prescribing. Pharm J. 2004; 273:407. News.

26. Chief pharmacists: "state of the nation." Pharm J. 2004; 273:484. News.

27. Medicines and Healthcare Products Regulatory Agency. Consultation on proposals to introduce independent prescribing by pharmacists. www.dh.gov.uk/ assetRoot/04/10/48/81/04104881.pdf (accessed 2005 Nov 9).

28. Silcock J. Raynor DK, Petty D. The organisation and development of primary care pharmacy in the United Kingdom. Health Policy. 2004; 67:207-14.

29. Grice P, ed. Chemist and druggist directory. London: Miller Freeman; 1998.

30. Child D, Cantrill J, Cooke J. Effectiveness of hospital pharmacy: where is the evidence? www.ghp.org.uk/default.asp? cid=398\&ed=13185 (accessed 2005 Nov 9).

31. Medendium-informing primary care. Vol. 18. Berkhamsted, England: Medendium Group Publishing Ltd.; 2003.

32. Culshaw M, Dawes S. Assessing the value of a discharge pharmacist. Pharmacy Manage. 1998; 14(2):22-3.

33. Jacklin A, Patel K, Almossawi O. A discharge pharmacist service improves the timeliness, quality and cost of discharge. Pharm Pract. 2001; 11:100-2.

34. A spoonful of sugar: medicines management in NHS hospitals. www.auditcommission.gov.uk/Products/NATIONALREPORT/E83C8921-6CEA-4b2c-83E7F80954A80F85/nrspoonfulsugar.pdf (accessed 2005 Nov 9).

35. Barrett JM, Hebron B. An examination of the impact of a ward-based pharmacist on the ability of a diabetes medical ward to cope with winter pressures. Pharm J. 2002; 268:28-31.

36. Bellingham C. How supplementary prescribing helps in both acute and chronic hospital care. Pharm J. 2004; 272:640-1. News.

37. London pharmacists secure training funds for supplementary prescribing. Pharm J. 2003; 271:399. News.

38. Murphy A, Scott A. Artificial nutritional support: what are the options? Hosp Pharm. 2000; 7:146-54.

39. Blake D. My career as ... a cancer services pharmacist. Hosp Pharm. 2004; 11:146-51.

40. Horne AL, Dapolite LA. Protocol for pharmacist management of antineoplastic drug-induced adverse effects in outpatients. Am J Health-Syst Pharm. 1997; 54:680-3.

41. Prescribing: new opportunities for all. Pharm J. 2003; 271:770. News.

42. Andalo D. Why one hospital pharmacist ventures into the community to run a CHD clinic. Pharm J. 2004; 273:56. 
43. Bellingham C. An insider's view of the supplementary prescribing course for pharmacists. Pharm J. 2003; 271:442.

44. Langleben D. Pharmacist's input into heart failure team reduces readmissions. Pharm J. 2002; 269:60.

45. Pharmacist-led CHD clinic keeps going. Pharm J. 2002; 268:312. News.

46. Hughes EC, John NR, Swithenbank PJ. Setting up and evaluating a pharmacistled outpatient DVT clinic. Pharm J. 1999; 263:R66-7.

47. Parekh R, Ghee C. Evaluation of a pharmacist controlled anticoagulant clinic. $\mathrm{Br}$ J Pharm Pract. 1987; 9:370-81.

48. Holden J, Holden K. Comparative effectiveness of general practitioner versus pharmacist dosing of patients requiring anticoagulation in the community. J Clin Pharm Ther. 2000; 25:49-54.

49. Radley AS, Hall J, Farrow M et al. Evaluation of anticoagulant control in a pharmacist operated anticoagulant clinic. J Clin Pathol. 1995; 48:545-7.

50. National Service Framework for renal services. Pharm J. 2004; 272:75. News.

51. Medicine review clinics for renal patients. Pharm J. 2000; 265:23. News.

52. Capper E, Jones SW. Are patients satisfied with a pharmacist-led rheumatology drug monitoring clinic? Pharm J. 1999; 263:R66.

53. Department of Health. National Service Framework for older people. www. dh.gov.uk/assetRoot/04/07/12/83/ 04071283.pdf (accessed 2005 Nov 9).

54. Department of Health. National Service Framework for renal services. Part one: dialysis and transplantation. www. dh.gov.uk/assetRoot/04/07/05/25/ 04070525.pdf (accessed 2005 Nov 9).

55. Shah R. Medicines management. Pharm J. 1997; 259:26.

56. Smith H. Pharmacist involvement in a surgical preadmission clinic improves the quality of patient care. Pharm J. 1997; 259:902.

57. Jay C. The role of the pre-admissions pharmacist. Hosp Pharm. 1998; 5:105-6.

58. Spiller C, Ashcroft D. Controlled trial of a pharmacist-led surgical pre-admission clinic in secondary care. Int $J$ Pharm Pract. 2004; 12:R31.

59. General Practitioners Committee. New GMS contract explained. www.bma.org. uk/ (accessed 2004 Jan 10).

60. Department of Health. National Service Framework for coronary heart disease. www.dhs.gov.uk/assetRoot/04/05/75/26/ 04057526.pdf (accessed 2005 Nov 9).

61. Department of Health. National Service Framework for diabetes: standards. www.dh.gov.uk/assetRoot/04/05/89/38/ 04058938.pdf (accessed 2005 Nov 9).

62. British Thoracic Society and Scottish Intercollegiate Guidelines Network. British guideline on the management of asthma. www.enterpriseportal2.co.uk/filestore/ bts/asthmafull.pdf (accessed 2005 Nov 9).

63. National Institute for Clinical Excellence. Management of chronic obstructive pulmonary disease in adults in primary and secondary care. www.nice.org.uk/pdf/ CG012_niceguideline.pdf (accessed 2005 Nov 9).

64. Williams B, Poulter NR, Brown MJ et al. British Hypertension Society guidelines for hypertension management 2004 (BHS-IV): summary. BMJ. 2004 328:634-40. [Erratum, BMJ. 2004; 328 . 926.]

65. Department of Health. National Service Framework for mental health: modern standards and service models for mental health. www.dh.gov.uk/assetRoot/04/01/ 26/60/04012660.pdf (accessed 2005 Nov 9).

66. Feetam C, Newton G. Pharmacist prescribing in mental health. Hosp Pharm. 2004; 11:76-7.

67. Hay A, Bradley E, Nolan P. Supplementary nurse precribing. Nurs Stand. 2004; 18:33-9.

68. Antoniou S, Webb DG, Davies JG et al. General level competency framework improves the clinical practice of hospital pharmacists: final results of the South of England Trial. Int I Pharm Pract. 2004; 12:R22-3.

69. Department of Health. A sweet pill for pharmacists. www.dh.gov.uk/ PublicationsAndStatistics/PressReleases/ Press Releases Notices/f s / en? CONTENT_ID $=4091698 \& \mathrm{chk}=\mathrm{yNYBq7}$ (accessed 2005 Nov 9).

70. Bellingham $\mathrm{C}$. What the new contract has in store. Pharm J. 2004; 273:385.

71. Walshe K, Smith J, Dixon J et al. Primary care trusts. BMJ. 2004; 329:871-2 Editorial.

72. Sexton J, Ho YJ, Green CF et al. Ensuring seamless care at hospital discharge: a national survey. J Clin Pharm Ther. 2000; 25:385-93.

73. Wilkie P, Sibbald B, Raftery J et al. Prescribing at the hospital-general practice interface I: hospital outpatient dispensing policies in England. BMJ. 1992; 304:2931 .

\section{Appendix-Terms used to describe health care professionals and the health care system in England}

Chief pharmacist: The pharmacy lead for the trust (primary or secondary) in all aspects of pharmacy services.

Clinical diploma: A postgraduate course which qualified pharmacists can undertake, which comprises of advanced level clinical pharmacy.
Clinical governance: The system of steps and procedures adopted by the National Health Service to ensure that patients receive the highest possible quality of care.

D grade pharmacist: Usually has a postgraduate qualification and at least five years of clinical experience. The pharmacist will normally specialize in a clinical area.

District general hospital: The most common type of hospital within the United Kingdom and deals with patients who are acutely ill.

E grade nurse: Usually has a minimum of six months postregistration experience. Nurses specialize in a clinical area at this level by taking postregistration courses.

E grade pharmacist: Has more clinical experience and expertise. The pharmacist's role may also include some form of staff and budget management.

First-level registered nurse: A nurse who is registered in subpart 1 of the nurses' part of the professional register.

Fully registered: Health care professionals who have completed the required training program and become recognized as a qualified professional by having their name on their profession's register.

Junior doctor: The first year after completion of undergraduate medical training (preregistration).

National Service Framework: Provides long-term strategies for improving specific areas of care. These government documents set out the targets for evidence-based medicine in specific disease areas or population groups.

Primary care trust: An organizational framework for the control of primary health services that consist of general practitioners and other health care professionals. These trusts are responsible for the planning and securing of health services and improving the health of a local population.

Secondary care trust: An organizational framework responsible for the provision of health care services provided by medical specialists. These trusts are found in most large towns and cities.

Strategic health authority: England is divided into 28 strategic health authorities. They are responsible for developing strategies for the local health services and ensuring high-quality performance. They manage the National Health Service locally and are a key link between the Department of Health and the National Health Service. They also ensure that national priorities (such as programs for improving cancer services) are integrated into local plans.

Tertiary specialist hospital: An institution that acts as a regional or national center of expertise within a trust for more specialized care or that is attached to a university for the training of health professionals. 
Copyright of American Journal of Health-System Pharmacy is the property of American Society of Health System Pharmacists and its content may not be copied or emailed to multiple sites or posted to a listserv without the copyright holder's express written permission. However, users may print, download, or email articles for individual use. 